Annals of International Medical and Dental Research

E-ISSN: 2395-2822 | P-ISSN: 2395-2814

Vol-8, Issue-1 | January-February 2022

DOI: $10.53339 /$ aimdr.2022.8.1.38

Page no- 296-309 | Section- Research Article (Medicine)

\title{
High Risk Foot Among Type-2 Diabetes Mellitus Patients in a Tertiary Care Hospital
}

\section{S. M. Mohiuddin ${ }^{*}$, Sayeqa Nasreen Khondker², Tofail Ahmed ${ }^{3}$}

\begin{abstract}
${ }^{1}$ Assistant Professor, Endocrinology and Diabetes, Sir Salimullah Medical College, Dhaka, Bangladesh.

Email: mohisomc32@gmail.com

Orcid ID: 0000-0002-0315-2013.

${ }^{2}$ Assistant Professor, Burn and Plastic Surgery, Sir Salimullah Medical College, Dhaka, Bangladesh.

Email: shaplass25@gmail.com

Orcid ID: 0000-0002-3954-8263.

3Professor of Endocrinology, CEO DLP Bangladesh Diabetic Association, Dhaka Bangladesh.

Email: tofail.ahmed@yahoo.com

Orcid ID: 0000-0001-5652-0732
\end{abstract}

*Corresponding author

\begin{abstract}
Background: Feet of diabetic persons are at a high risk of developing complications and their prevalence is very high. Uncontrolled diabetes i.e. hyperglycemia particularly chronic hyperglycemia plays the most critical role in developing all forms of macro and microvascular complications in foot. The "high risk foot" can be identified by simple clinical examination. A structured screening program for "High Risk Foot" integrated with all diabetic care units is essential. Objectives: The study was initiated to determine the frequency of "high-risk foot" among Type 2 diabetic patients. Methods: It was a crosssectional observational study, conducted among 324 Type 2 diabetic patients attending BIRDEM General Hospital, Dhaka, Bangladesh. All participants were interviewed by an administered questionnaire, underwent clinical examination and review of medical records from the diabetic guide book of the patients and hospital records. Results: Among a total of 324 patients, 198(61\%) patients were having high-risk feet. Of the diabetics with high risk foot- loss of protective sensation $73.2 \%$; absent pedal pulse $23.2 \%$; history foot ulcer $25.3 \%$; limited joint mobility $15.2 \%$; foot deformity $11.1 \%$ and previous foot amputation $3.5 \%$. The study population had poor glycemic status (HbA1c $10.81+5.23 \%)$. Other variables age $55.43( \pm 11.062)$ years; BMI: $25.33+5.7 \mathrm{~kg} / \mathrm{m}^{2}$; duration of diabetes $14.24+7.25$ years; sex ratio (M: F) 1.3:1; family history of DM 71.9\%; hypertensive 53.1\%; smoker 73.5\%; dislipidemia 52.8\%, albuminuria $58.6 \%$, and retinopathy $53.7 \%$. Males are significantly higher in the high-risk foot. Conclusion: This study documented a very high frequency of high risks foot in our diabetic population. Peripheral Neuropathy (PN) and PVD are two common forms of high risk foot and these are influenced by a longer duration of diabetes, the presence of albuminuria for $\mathrm{PN}$, and retinopathy. Male sex, longer duration of diabetes, presence of hypertension and smoking for PVD. Regular foot examination and treatment to target patients will modify the modifiable risk factors and thereby prevent foot ulcers and amputation.
\end{abstract}

Received: 04 October 2021

Revised: 04 November 2021

Accepted: 15 November 2021

Published: 22 December 2021

Keywords:- Diabetic foot, Type 2 Diabetes, High risk foot, Peripheral Neuropathy, Peripheral vascular disease.

\section{INTRODUCTION}

Diabetes mellitus (DM) is defined as a group of metabolic diseases characterized by hyperglycemia resulting from defects in insulin secretion, insulin action, or both.[1] Diabetes mellitus is classified on the basis of etiology and clinical presentation of the disorder into four 
Annals of International Medical and Dental Research

E-ISSN: 2395-2822 | P-ISSN: 2395-2814

Vol-8, Issue-1 | January-February 2022

DOI: 10.53339/aimdr.2022.8.1.38

Page no- 296-309 | Section- Research Article (Medicine)

types: type1diabetes, type 2 diabetes, other specific types, and gestational diabetes.[2] In 2019, global estimates of people with diabetes is 463 million, projected to reach 700 million by 2045 and the prevalence of diabetes would rise from $8.3 \%$ to $9.6 \%$ by 2045. [3] Diabetes is the fifth leading cause of death in the world which accounts for about 4.2 million deaths annually. ${ }^{[3,4]}$ Prevalence of diabetes is increasing at an alarming rate all over the world. [5] The low and middle-income countries, in particular are the major contributors (about three quarters) to the global burden of diabetes. $[3,6]$ China and India hold the $1^{\text {st }}$ and $2^{\text {nd }}$ position respectively having 116.4 and 77.0 millions of total cases of diabetes in adult population in 2019.[3] It is anticipated that more than $80 \%$ of the world's population with diabetes will come from developing countries and by the year 2030 more than $60 \%$ of the world's population with diabetes is expected to be living in Asia.[7] In 2019, it was estimated that 8.4 million of the Bangladeshi population were diabetic.[3] Compared with the previous reports of Bangladesh and other Asian studies, the prevalence of diabetes and IFG in the rural population was found to be on the increase. Older age, higher obesity, higher income, family history of diabetes, and reduced physical activity were proved significant risk factors for diabetes and IFG. [] Foot ulcerations are one of the most common complications in patients with diabetes. It has been estimated that the lifetime risk of a patient with diabetes developing a foot ulcer may be as high as $25 \%$ and at any one time in western countries, $2 \%$ $3 \%$ of diabetic patients are likely to have active foot ulceration. [9,10] Diabetic Foot Ulcer (DFU) affects $15 \%$ of people with diabetes.[11] DFUs typically result from peripheral neuropathy and/or large vessel disease. But most commonly DFUs are caused by peripheral neuropathy complicated by deformity, callus and trauma.[12] Vascular insufficiencies, infections, and failure to implement effective treatment of DFUs are linked to secondary medical complications, such as osteomyelitis and amputation. [13] The factors predispose to tissue damage in the diabetic foot are neuropathy, peripheral vascular disease, and infection. From the practical point of view, the diabetic foot can generally be considered as one of two entities: the neuropathic foot and ischaemic foot. In a neuropathic foot, somatic and autonomic nerve fibers have been damaged but the circulation is intact and pulses palpable, resulting in a warm, numb, and dry foot. Neuropathy develops in both type- 1 and type- 2 patients with longstanding diabetes. The most common manifestation is peripheral neuropathy of the foot and ulcers can occur on the weight-bearing surface. The incidence of peripheral neuropathy (PN) in T2DM is 30\%.[14] A study conducted in BIRDEM Hospital in Bangladesh showed the overall prevalence of diabetic peripheral neuropathy (DPN) as 19.7\%.[15] A study conducted in Sweden showed the prevalence of DPN was 57\%.116] General healing rates for neuropathic DFUs have been reported in the literature.[17] The ischaemic foot has reduced blood supply, but usually also shows a variable degree of neuropathy and so should strictly be termed as the neuroischaemic foot is usually cold and pulseless and may be complicated by rest-pain, ulceration due to localized pressure necrosis and ultimately gangrene formation. Peripheral arterial disease (PAD) is a chronic atherosclerotic process that causes narrowing of peripheral arterial vasculature, mainly of the lower limbs which 
Annals of International Medical and Dental Research

E-ISSN: 2395-2822 | P-ISSN: 2395-2814

Vol-8, Issue-1 | January-February 2022

DOI: $10.53339 /$ aimdr.2022.8.1.38

Page no- 296-309 | Section- Research Article (Medicine)

has an estimated worldwide prevalence of up to $10 \%$, increasing to about $30 \%$ in patients more than 50 years of age.18] Patients with diabetes have a 4-fold increased risk of developing PAD which presents at an earlier stage and progresses more rapidly than in people without diabetes. [19] The larger arteries are affected in the same way as for non-diabetics, but those of the calf are involved to a greater extent. [20] Hyperglycemia appears to be directly related to the susceptibility to infection. When glucose concentrations exceed $240 \mathrm{mg} / \mathrm{dl}$, neutrophilic chemotaxis is impaired.[21] It has also been shown that elevated plasma glucose levels in the postoperative period increases the risk of infection. [22] Chronic hyperglycemias have also been shown to diminish a patient's capacity to heal wounds after surgery. Although the precise mechanism remains unknown, hyperglycemia increases the presence of microvascular and macrovascular diseases, decrease phagocytosis, chemotaxis, and polymorphonuclear leukocyte mobilization. [23] Growth factors such as VEGF, PDGF, and KGF may also be produced at lower levels or in less effective forms.[24] Skin fibroblast proliferation has also been shown to decrease in the presence of hyperglycemia.[25] Diabetic foot ulcers and infections are usually initiated by minor trauma and can become extensive, deep, and spreading. These infections require surgical drainage and debridement, which frequently involves amputation at the toes, the trans metatarsal level, or even the foot or leg. In patients with major foot infections and signs of spreading sepsis, antibiotics active over a wide spectrum of organisms including anaerobes, are indicated. Diabetic foot problems are a global burden and the consequences are major. There is an increase in amputation rates globally despite increased foot care education, research, and prevention. This has been attributed mainly to diabetes and the failure of early detection of the risk group. As it is a complication that is preventable by simple measures that can largely be taken by the patient himself. Frequent clinical examination of the feet and related systems forms the mainstay of detecting diabetic foot; investigations are only an adjunct to clinical examination. The treatment is usually conservative and a limb sparing approach is used, along with proper diabetes control. Early detection and management of aetiological factors like vasculopathy, neuropathy and infection is essential to get good outcomes. Amputation is usually used as a last resort in non- salvageable limbs. Above all, this is one condition which proves the maxim that "prevention is better than cure".[26]

\section{Objectives}

To detect high risk foot among type 2 diabetic patients and to determine its frequency.

\section{MATERIAL AND METHODS}

It was a cross-sectional observational study, conducted at Bangladesh Institute of Research \& Rehabilitation in Diabetes, Endocrine and Metabolic Disorders (BIRDEM), Dhaka from July 2013 to June 2014. The adult patient of more than 18 years type 2 diabetic who fulfilled the inclusion criteria attending both out-patient \& in-patient departments were enrolled in the study as the study population. Patients suffering from severe co-morbid conditions (ESRD, severe heart failure, liver failure, respiratory failure), type 1 diabetes, GDM, other specific type of diabetes and patients with impaired glucose tolerance or impaired fasting 
Annals of International Medical and Dental Research

E-ISSN: 2395-2822 | P-ISSN: 2395-2814

Vol-8, Issue-1 | January-February 2022

DOI: $10.53339 /$ aimdr.2022.8.1.38

Page no- 296-309 | Section- Research Article (Medicine)

glucose were excluded in this study. The information regarding demographics, socioeconomic, and lifestyle characteristics were collected by interviewing the participant. Complete history and physical examinations were done. Weight and height were measured with minimal clothes without shoes and BMI $(\mathrm{kg} / \mathrm{m} 2)$ was calculated. Both feet were examined for signs of vasculopathy (assessment of pedal pulses) and neuropathy (using 10-gm monofilament, $128-\mathrm{Hz}$ tuning fork, percussion hammer) including the presence of deformities, callus, limited joint mobility. History of ulceration, gangrene, and amputation were also noted. From the patient's guidebook and hospital records, diagnosis and diseases related recent biochemical data (within the last 6 months) were collected. Ethical approval from the ethical approval committee of the Diabetes Association of Bangladesh was obtained prior to the commencement of the study. From the participants informed written consent was taken. SPSS version 19.0. used for data analysis. Individual risk factors were identified through Multivariate analysis and the possible confounders were adjusted. Odds Ratio with 95\% CI was generated through binary logistic regression to assess individual refractors adjusting for all possible confounders. A value of $p<0.05$ was considered statistically significant.

\section{RESULTS}

In 324 type 2 diabetic patients, mean age was 55.43 ( \pm 11.062 ) years \& median was 56.0. SD 11.064, SE 0.615, range (30-80); CI (54.22-56.64), male female ratio was 1.3:1. Most of the patients were $\geq 60$ years old. Most of the patients were educated up to various levels. More than half of the patients were either current or ex-smokers.
Considerable percentages of the patients (44\%) were overweight or obese. High risk foot was diagnosed on the basis of the presence of one or more of the following factors:loss of protective sensation, absent pedal pulse, foot deformity, limited joint mobility, history of foot ulcer and previous amputation. Among them 61\% (198) were having high risk foot. Risk factors were loss of protective sensation $44.7 \%$ (145), H/O foot ulcer $15.43 \%$ (50), absent pedal pulse $14.20 \%$ (46), limited joint mobility $9.26 \%$ (30), foot deformity $6.79 \%$ (22) and $\mathrm{H} / \mathrm{O}$ previous amputation $2.16 \%$ (7).

Among total 324 patients, 44\% were diagnosed through screenings and $35 \%$ by symptoms. Incidental diagnosis was less. More than $34 \%$ of the patients had the disease for $\geq 10$ years. Of the total population $53 \%$ had hypertension. Importantly, $72 \%$ had family history of DM. Peripheral neuropathy was present in more than half of the patients (54\%) while the frequency of peripheral vascular disease was less $(14.2 \%)$ [Table 2].

High total cholesterol was present in $31.5 \%$, high triglycerides in $43 \%$, high LDL in $18.8 \%$ while low HDL was present in $52.5 \%$ of the study population. The analysis of glycaemic control using $\mathrm{HbA} 1 \mathrm{C}$ showed that $28 \%$ had good control [Table 3].

The parameters on which high risk foot was diagnosed are given in the table 4 . Among the 198 Diabetic patients with High risk foot - Loss of protective sensation was reported in 145 patients $(73.2 \%)$; Fifty patients(25.3\%) had history of foot ulceration; Pedal pulse was absent in 46 patients $(23.2 \%)$ while 30 patients $(15.2 \%)$ had limited joint mobility and 22 
Annals of International Medical and Dental Research

E-ISSN: 2395-2822 | P-ISSN: 2395-2814

Vol-8, Issue-1 | January-February 2022

DOI: $10.53339 /$ aimdr.2022.8.1.38

Page no- 296-309 | Section- Research Article (Medicine)

patients $(11.1 \%)$ had foot deformity and 7 patients $(3.5 \%)$ had history of foot amputation.

The number of current smokers and ex-smokers were significantly higher in high risk group. Non-smokers were almost equal in both groups [Table 5].

In controlled diabetes group the frequency of high risk foot was less but in uncontrolled diabetes group this was significantly higher [Table 6].

Old patients suffered from the condition significantly more than relatively younger ones. Longer duration of DM, presence of albuminuria, poor control of DM and presence of retinopathy were significantly related to $\mathrm{PN}$ [Table 7].

Cross tabulation between peripheral vascular diseases (PVD) and different variables are showed in [Table 8]. No difference was observed for gender or age while presence of retinopathy and hypertension were significantly related to PVD.
The multivariate stepwise logistic regression analysis of PN on variables including sex, level of education, age group, duration of disease, presence of retinopathy, albuminuria, and $\mathrm{HbA1c}$, showed that PN was only significantly associated with increased duration of disease $(p=0.002)$, presence of albuminuria $(p=0.012)$ and presence of retinopathy $(p<0.001)$ [Table 9].

The multivariate stepwise logistic regression analysis of PVD on variables including sex, age group, level of education, duration of disease, presence of hypertension, $\mathrm{HbA} 1 \mathrm{C}$ and presence of albuminuria revealed that only male, (adjusted OR: 0.254; 95\% CI: 0.132-0.631), increased DM duration (adjusted OR: 0.452; 95\% CI: $0.278-0.682)$, low level of education (adjusted OR: 2.371; 95\% CI: 1.03-3.720), presence of hypertension (adjusted OR: 1.352; 95\% CI: 0.83-2.20) and H/O smoking (adjusted OR: $1.321 ; 95 \%$ CI: 0.81-2.17) were significantly associated with PVD [Table 10].

Table 1: Socio-demographic characteristics of the patients $(\mathrm{N}=324)$.

\begin{tabular}{|l|l|l|}
\hline Variables & Frequency (n) & Percent (\%) \\
\hline Gender & & \\
\hline Male & 183 & 56.5 \\
\hline Female & 141 & 43.5 \\
\hline Age group (yrs.) & & \\
\hline$\leq 40$ & 35 & 10.8 \\
\hline $41-49$ & 64 & 19.7 \\
\hline $50-59$ & 88 & 27.2 \\
\hline$\geq 60$ & 137 & 42.3 \\
\hline Smoking \& tobacco use & & \\
\hline Current smoker & 59 & 18.21 \\
\hline Ex-smoker & 91 & 28.09 \\
\hline
\end{tabular}


Annals of International Medical and Dental Research

E-ISSN: 2395-2822 | P-ISSN: 2395-2814

Vol-8, Issue-1 | January-February 2022

DOI: $10.53339 /$ aimdr.2022.8.1.38

Page no- 296-309 | Section- Research Article (Medicine)

\begin{tabular}{|l|l|l|}
\hline Non smoker & 150 & 46.30 \\
\hline Tobacco user & 24 & 7.41 \\
\hline BMI group & & \\
\hline Under weight & 18 & 5.6 \\
\hline Normal weight & 163 & 50.3 \\
\hline Over weight & 96 & 29.6 \\
\hline Obese & 47 & 14.5 \\
\hline
\end{tabular}

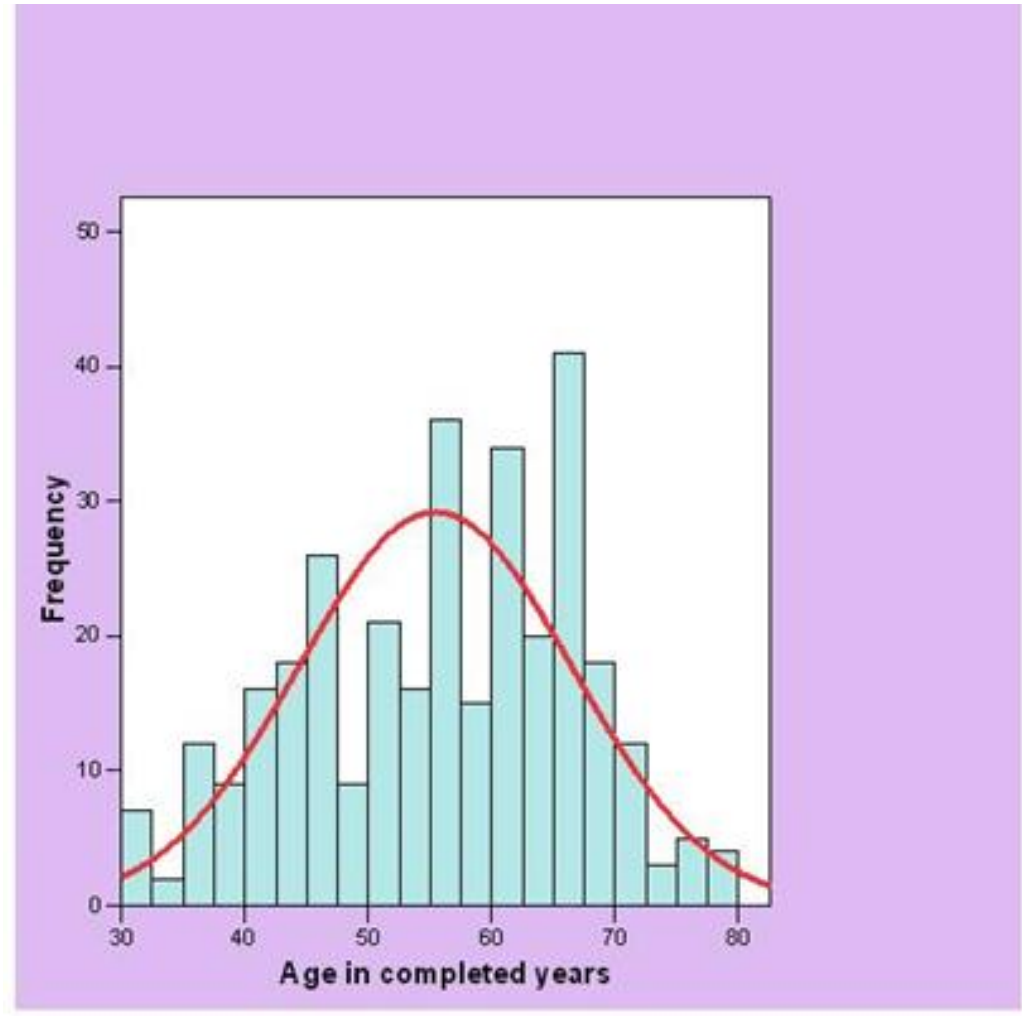

Figure 1: Age distribution of the patients

Table 2: Clinical characteristics of Type 2 diabetes patients $(\mathrm{N}=324)$.

\begin{tabular}{|l|l|l|}
\hline Variables & Frequency (n) & Percent (\%) \\
\hline Mode of diagnosis & & \\
\hline Incidental & 68 & 21.0 \\
\hline Screening & 142 & 43.8 \\
\hline Symptomatic & 114 & 35.2 \\
\hline F/H of diseases & & \\
\hline Diabetes & 233 & 71.91 \\
\hline Hypertension & 128 & 39.51 \\
\hline Ischemic Heart Disease & 29 & 8.95 \\
\hline
\end{tabular}


Annals of International Medical and Dental Research

E-ISSN: 2395-2822 | P-ISSN: 2395-2814

Vol-8, Issue-1 | January-February 2022

DOI: $10.53339 /$ aimdr.2022.8.1.38

Page no- 296-309 | Section- Research Article (Medicine)

\begin{tabular}{|l|l|l|}
\hline Duration of Diabetes & & \\
\hline$<1$ year & 29 & 9.0 \\
\hline $1-5$ years & 119 & 36.7 \\
\hline $6-10$ years & 58 & 17.9 \\
\hline $11-20$ years & 90 & 27.8 \\
\hline$>21$ years & 28 & 8.6 \\
\hline Hypertension & & \\
\hline Present & 172 & 53.1 \\
\hline Absent & 152 & 46.9 \\
\hline Peripheral neuropathy & & \\
\hline Present & 175 & 54.0 \\
\hline Absent & 149 & 46.0 \\
\hline Peripheral vascular disease & & \\
\hline Present & 46 & 14.2 \\
\hline Absent & 278 & 85.8 \\
\hline
\end{tabular}

Table 3: Lipid profile and some other investigations of patients ( $N=324)$

\begin{tabular}{|l|l|l|}
\hline Variables & Frequency (n) & Percent (\%) \\
\hline Total cholesterol & & \\
\hline High $(>200 \mathrm{mg} / \mathrm{dL})$ & 102 & 31.5 \\
\hline Normal $(\leq 200 \mathrm{mg} / \mathrm{dL})$ & 222 & 68.5 \\
\hline Triglyceride & & \\
\hline High $(>150 \mathrm{mg} / \mathrm{dL})$ & 140 & 43.21 \\
\hline Normal $(\leq 150 \mathrm{mg} / \mathrm{dL})$ & 184 & 56.79 \\
\hline HDL & & 47.53 \\
\hline High $(>40 \mathrm{mg} / \mathrm{dL})$ & 154 & 52.47 \\
\hline Low $(\leq 40 \mathrm{mg} / \mathrm{dL})$ & 170 & \\
\hline LDL & & 18.83 \\
\hline High $(>100 \mathrm{mg} / \mathrm{dL})$ & 61 & 81.17 \\
\hline Normal $(\leq 100 \mathrm{mg} / \mathrm{dL})$ & 263 & \\
\hline Albuminuria & & 58.64 \\
\hline Present & 190 & 41.36 \\
\hline Absent & 134 & \\
\hline HbA1C & & 28.09 \\
\hline Good control $(<7 \%)$ & 91 & 71.91 \\
\hline Poor control $(\geq 7 \%)$ & 233 & \\
\hline
\end{tabular}


Annals of International Medical and Dental Research

E-ISSN: 2395-2822 | P-ISSN: 2395-2814

Vol-8, Issue-1 | January-February 2022

DOI: $10.53339 /$ aimdr.2022.8.1.38

Page no- 296-309 | Section- Research Article (Medicine)

\section{Distribution of High Risk Foot of Participants}

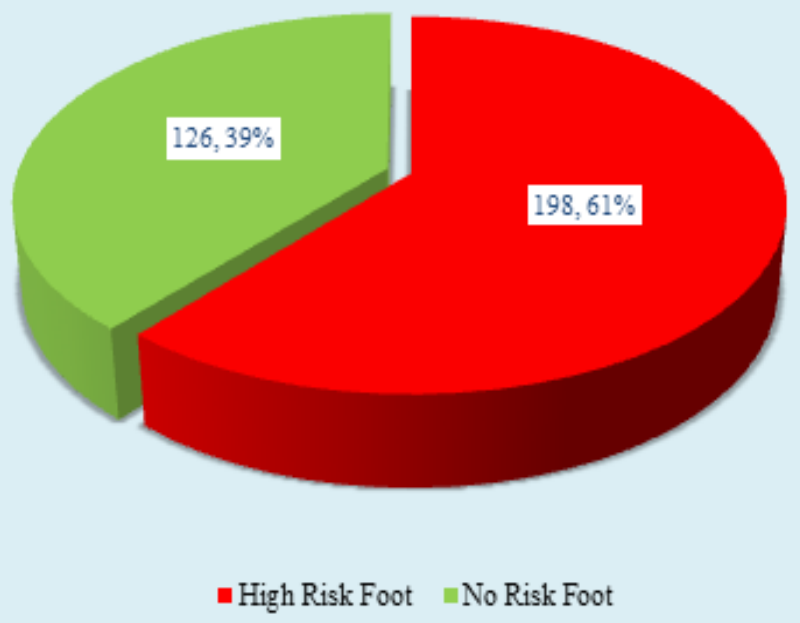

Figure 2: Pie diagram showing high risk foot among type 2 diabetic subjects $(\mathrm{N}=324)$

Table 4: Conditions lead to high risk foot( $\mathrm{N}=198)$

\begin{tabular}{|l|l|l|}
\hline Variables & Frequency (n) & Percent (\%) \\
\hline Loss of protective sensation & 145 & 73.2 \\
\hline H/O foot ulcer & 50 & 25.3 \\
\hline Absent pedal pulse & 46 & 23.2 \\
\hline Limited joint mobility & 30 & 15.2 \\
\hline Foot deformity & 22 & 11.1 \\
\hline H/O previous amputation & 7 & 3.5 \\
\hline
\end{tabular}

Table 5: Cross tabulation between smoking habits and high risk foot $(\mathrm{N}=324)$

\begin{tabular}{|l|l|l|l|}
\hline \multirow{2}{*}{ Habits of smoking } & \multicolumn{2}{|l|}{ High risk foot } & \multirow{2}{*}{ p-Value } \\
\cline { 2 - 3 } & Yes n (\%) & No n (\%) & \multirow{2}{*}{$<0.001^{\mathrm{s}}$} \\
\hline Current smoker & $65(32.8)$ & $38(30.2)$ & \\
\hline Ex-smoker & $76(38.4)$ & $21(16.7)$ & \\
\hline Non- smoker & $44(22.2)$ & $42(33.3)$ & \\
\hline Tobacco user & $13(6.6)$ & $25(19.7)$ & \\
\hline
\end{tabular}

Table 6: Cross tabulation between status of diabetes and high risk foot $(\mathrm{N}=324)$

\begin{tabular}{|l|l|l|l|}
\hline \multirow{2}{*}{ Diabetes Status } & \multicolumn{2}{|l|}{ High risk foot } & \multirow{2}{*}{ p-Value } \\
\cline { 2 - 3 } & Yes n (\%) & No n (\%) & \\
\hline Controlled & $24(12.1)$ & $67(53.2)$ & $<0.001^{\mathrm{s}}$ \\
\hline uncontrolled & $174(87.9)$ & $59(46.8)$ & \\
\hline
\end{tabular}


Annals of International Medical and Dental Research E-ISSN: 2395-2822 | P-ISSN: 2395-2814

Vol-8, Issue-1 | January-February 2022 DOI: $10.53339 /$ aimdr.2022.8.1.38 Page no- 296-309 | Section- Research Article (Medicine)

Table 7: Peripheral Neuropathy in relation to baseline characteristics of the study population

\begin{tabular}{|c|c|c|c|}
\hline \multirow[t]{2}{*}{ Variables } & \multicolumn{2}{|c|}{ Peripheral Neuropathy } & \multirow[t]{2}{*}{ p-Value } \\
\hline & Present n (\%) & Absent n (\%) & \\
\hline \multicolumn{4}{|l|}{ Gender } \\
\hline Male & $104(59.4)$ & $79(53.0)$ & \multirow[t]{2}{*}{0.246} \\
\hline Female & $71(40.6)$ & $70(47.0)$ & \\
\hline \multicolumn{4}{|l|}{ Age group } \\
\hline Up to 40 years & $19(10.9)$ & $16(10.7)$ & \multirow[t]{5}{*}{$0.007^{\mathrm{s}}$} \\
\hline $41-49$ years & $31(17.7)$ & $33(22.1)$ & \\
\hline $50-59$ years & $61(34.9)$ & $27(18.1)$ & \\
\hline$\geq 60$ years & $64(36.6)$ & $73(49.0)$ & \\
\hline \multicolumn{3}{|c|}{ Duration of the disease } & \\
\hline$<1$ year & $7(4.1)$ & $14(9.6)$ & \multirow[t]{5}{*}{$<0.001^{\mathrm{s}}$} \\
\hline $1-5$ years & $40(23.5)$ & $79(54.1)$ & \\
\hline 6-10 years & $38(22.4)$ & $20(13.7)$ & \\
\hline $11-20$ years & $67(39.4)$ & $23(15.8)$ & \\
\hline$>21$ years & $18(10.6)$ & $10(6.8)$ & \\
\hline \multicolumn{4}{|l|}{ Albuminuria } \\
\hline Present & $109(62.3)$ & $21(14.1)$ & \multirow[t]{2}{*}{$<0.001^{\mathrm{s}}$} \\
\hline Absent & $66(37.7)$ & $128(85.9)$ & \\
\hline \multicolumn{4}{|l|}{$\mathrm{HbA1C}$} \\
\hline Good control $(<7 \%)$ & $44(25.1)$ & $102(68.5)$ & \multirow[t]{2}{*}{$<0.001^{\mathrm{s}}$} \\
\hline Poor control (> 7\%) & 131(74.9) & $47(31.5)$ & \\
\hline \multicolumn{4}{|l|}{ Retinopathy } \\
\hline Present & $141(80.6)$ & $33(22.1)$ & \multirow[t]{2}{*}{$0.002^{\mathrm{s}}$} \\
\hline Absent & $34(19.4)$ & $116(77.9)$ & \\
\hline
\end{tabular}

Table 8: Peripheral Vascular Disease in relation to baseline characteristics of the study population

\begin{tabular}{|l|l|l|l|}
\hline \multirow{2}{*}{ Variables } & \multicolumn{2}{|l|}{ Peripheral Vascular Disease } & \multirow{2}{*}{ p-Value } \\
\cline { 2 - 3 } & Present n (\%) & Absent n (\%) & \\
\hline Gender & & & \\
\hline Male & $28(60.9)$ & $155(55.8)$ & 0.517 \\
\hline Female & $18(39.1)$ & $123(44.2)$ & \\
\hline Age group & & & \multirow{2}{*}{0.074} \\
\hline Up to 40 years & $1(2.2)$ & $34(12.2)$ & \\
\hline $41-49$ years & $14(30.4)$ & $50(18.0)$ & \\
\hline $50-59$ years & $13(28.3)$ & $75(27.0)$ & \\
\hline$\geq 60$ years & $18(39.1)$ & $119(42.8)$ & \\
\hline
\end{tabular}


Annals of International Medical and Dental Research

E-ISSN: 2395-2822 | P-ISSN: 2395-2814

Vol-8, Issue-1 | January-February 2022

DOI: 10.53339 /aimdr.2022.8.1.38

Page no- 296-309 | Section- Research Article (Medicine)

\begin{tabular}{|l|l|l|l|}
\hline Retinopathy & & & \\
\hline Present & $34(73.9)$ & $140(50.4)$ & \multirow{2}{*}{$0.003^{\mathrm{s}}$} \\
\hline Absent & $12(26.1)$ & $138(49.6)$ & \\
\hline Coronary artery disease & & & \multirow{2}{*}{0.068} \\
\hline Present & $10(21.7)$ & $33(11.9)$ & \\
\hline Absent & $36(78.3)$ & $245(88.1)$ & \\
\hline Hypertension & & & $0.006^{s^{s}}$ \\
\hline Present & $33(71.7)$ & $139(50.0)$ & \\
\hline
\end{tabular}

Table 9: Multivariate analysis of risk factors for PN among DM patients using stepwise Logistic Regression

\begin{tabular}{|l|l|l|l|l|}
\hline Variable & $\begin{array}{l}\text { Regression } \\
\text { coefficient }\end{array}$ & p-Value & Adjusted OR & 95\% CI \\
\hline Increase DM duration & -0.491 & 0.002 & 0.67 & $0.056-0.96$ \\
\hline Presence of albuminuria & -0.547 & 0.012 & 0.59 & $0.38-0.78$ \\
\hline Presence of retinopathy & 2.590 & $<0.001$ & 1.37 & $0.52-3.620$ \\
\hline
\end{tabular}

Table 10: Multivariate analysis of risk factors for PVD among DM patients using stepwise Logistic Regression

\begin{tabular}{|l|l|l|l|l|}
\hline Variable & $\begin{array}{l}\text { Regression } \\
\text { coefficient }\end{array}$ & p-Value & Adjusted OR & 95\% CI \\
\hline Male & -1.435 & 0.013 & 0.254 & $0.132-0.631$ \\
\hline Increased DM duration & -0.765 & 0.012 & 0.452 & $0.278-0.682$ \\
\hline Low level of education & 0.876 & 0.002 & 2.371 & $1.03-3.720$ \\
\hline Presence of hypertension & 0.786 & 0.003 & 1.352 & $0.83-2.20$ \\
\hline H/O smoking & -1.287 & $<0.001$ & 1.321 & $0.81-2.17$ \\
\hline
\end{tabular}

\section{DISCUSSION}

The mean age of the patients was $55.43( \pm 11.062)$ years. Among total 324 patients, most of the patients were $\geq 60$ years and literate. Malefemale ratio was 1.3:1. More than half of the patients were either current or ex-smokers. $44 \%$ patients were diagnosed through screenings and $35 \%$ by symptoms. More than $34 \%$ of the patients had the disease for $\geq 10$ years. Of the total population, $53 \%$ had hypertension. $72 \%$ had a family history of DM which is consistent with other studies.[27, 28] High total cholesterol was present in $31.5 \%$, high triglycerides in $43 \%$, high LDL in $18.8 \%$ while low HDL was present in $52.5 \%$ of the study population. Other study reported high total cholesterol in $34.4 \%$, high triglycerides in $25.2 \%$, high LDL in $53.4 \%$ while low HDL in $25.7 \%$ study population. [27] The analysis of glycaemic control using $\mathrm{HbA} 1 \mathrm{C}$ showed that $28 \%$ had good control in contrast to $38 \%$.[27] The majority of patients who attended 100 diabetic patient care centers all 
Annals of International Medical and Dental Research

E-ISSN: 2395-2822 | P-ISSN: 2395-2814

Vol-8, Issue-1 | January-February 2022

DOI: 10.53339/aimdr.2022.8.1.38

Page no- 296-309 | Section- Research Article (Medicine)

over Bangladesh, had HbA1C and FPG levels above the recommended levels, and around $80 \%$ diabetic patients failed to achieve target glycaemic control.[29] The parameters on which high-risk foot was diagnosed were loss of protective sensation $(44.7 \%)$, history of foot ulceration $(15.43 \%)$, absent pedal pulse $(14.2 \%)$, limited joint mobility (9.3\%), and foot deformity $(6.8 \%)$ and 7 patients $(2.16 \%)$ had a history of foot amputation. On the basis of the presence of one or more parameters, 198 (61\%) patients were stratified as having high risk foot. This rate is high as some other studies reported lower rates.[28] Older patients significantly suffered more from the condition than relatively younger ones. As proved elsewhere, the current study results demonstrate that DM eventually leads to chronic complications, including PVD and $\mathrm{PN}$ which are known potential risk factors for foot complications. So, it is vital to observe PN and PVD among patients for diabetes foot complications. The results of this study showed that the overall frequency of $\mathrm{PN}$ was $54 \%$, which is almost similar to rates reported in other studies and higher than the equivalent rates reported in other study. ${ }^{[30,31]}$ The risk factors for neuropathy, predicted using univariate analysis were: age $(p=0.007)$, disease duration $(p<0.001)$, poor level of education $(p=0.001)$, and poor glycaemic control $(p<0.001)$. The complication was also highly significantly associated with other microangiopathic complications such as the presence of albuminuria $(\mathrm{p}<0.001)$ and diabetic retinopathy $(p=0.002)$. These findings are quite comparable to another study findings except that in their study male gender was also significantly associated with PN which was not the case in the present study.[27] Small sample size could be the cause for such a difference.
Comparatively, the rate revealed for PVD $(14.2 \%)$ in the study population was lower than that reported in other study populations, ${ }^{32]}$ but almost similar to UAE population which showed 12\% prevalence of PVD.27] However, the fact that $54 \%$ of the sample population have signs of neuropathy, is a clear indication that they are at increased risk of developing foot complications in the future. The high prevalence of PN compared with the relatively low prevalence of PVD in the study population can be due to methodological biases for diagnosing neuropathy and PVD. On univariate analysis predicted risk factors for PVD were: the presence of retinopathy $(p=0.003)$ and hypertension $(p=0.006)$. The multivariate stepwise logistic regression analysis of $\mathrm{PN}$ and PVD on variables including sex, level of education, age group, duration of disease, presence of hypertension, retinopathy, albuminuria, and $\mathrm{HbA1c}$, showed that $\mathrm{PN}$ was only significantly associated with increased duration of disease $(p=0.002)$, presence of albuminuria $(p=0.012)$ and presence of retinopathy $(\mathrm{p}<0.001)$. On the other hand, only males, (adjusted OR: 0.254; 95\% CI: 0.132-0.631), increased DM duration (adjusted OR: 0.452; 95\% CI: 0.278-0.682), low level of education (adjusted OR: 2.371; 95\% CI: 1.03-3.720), presence of hypertension (adjusted OR: 1.352; 95\% CI: 0.83-2.20) and H/O smoking (adjusted OR: 1.321 ; 95\% CI: 0.81-2.17) were significantly associated with PVD. The results are consistent with findings elsewhere. [33] It is interesting to note that albuminuria was the modifiable risk factor for PN, revealed in the study and the result is consistent with similar studies elsewhere.[34] However, some studies suggest that increased urinary albumin might be a marker for endothelial damage, the function of 
Annals of International Medical and Dental Research E-ISSN: 2395-2822 | P-ISSN: 2395-2814

Vol-8, Issue-1 | January-February 2022 DOI: 10.53339 /aimdr.2022.8.1.38

Page no- 296-309 | Section- Research Article (Medicine)

which may be the common cause of both microvascular and macrovascular diseases. $35,36,37]$ Similarly, the analysis revealed that hypertension is the modifiable risk factor for PVD in the study population, and the result is consistent with findings elsewhere.[38]

\section{Limitations of the study}

Assessment of inter-observer variability was not possible due to the single observer study design. For neuropathy, the study was unable to correlate the clinical findings with electrophysiological and morphologic findings such as nerve conduction studies. For diagnosis of PVD only presence or absence of peripheral pulse was used, measurement of Ankle Brachial Index (ABI) \& duplex ultrasound was not done.

\section{CONCLUSIONS}

It was observed that high-risk foot was related to a) loss of protective sensation like loss of vibration sense and ankle jerk; b) history of foot ulceration; c) absent pedal pulse that represented peripheral vascular disease and $d$ )

\section{REFERENCES}

1. American Diabetes Association. Diagnosis and classification of diabetes mellitus. Diabetes Care. 2009;32(Suppl 1):S62-S67. doi:10.2337/dc09-S062

2. American Diabetes Association. Diagnosis and classification of diabetes mellitus [published correction appears in Diabetes Care. Diabetes Care. 2010;33(Suppl 1):S62-S69. doi:10.2337/dc10-S062

3. Saeedi P, Petersohn I, Salpea P, Malanda B, Karuranga S, Unwin N, et al; IDF Diabetes Atlas Committee. Global and regional diabetes prevalence estimates for 2019 and projections for 2030 and 2045: Results from the International Diabetes Federation Diabetes Atlas, 9th edition. Diabetes Res Clin Pract. 2019;157:107843. doi: 10.1016/j.diabres.2019.107843. limited joint mobility. Of these, the most frequent findings were loss of sensation especially vibration sense, and loss of ankle jerk. More study is needed to confirm the study findings so that early detection may help to prevent foot ulcer and eventual amputation and disabilities.

\section{Recommendations}

It is essential to encourage physicians to pay more attention and care to foot examination, regular screening for foot complications to all diabetic patients especially among the elderly and illiterate patients, in view of the high reported rates of high-risk foot and to maintain glycaemia at a satisfactory level to reduce the risk of diabetes-associated complications. Emphasize the importance of regular screening for albuminuria and hypertension in diabetic patients as it is a modifiable risk factor for both microvascular and macrovascular complications. To improve patient's knowledge on risks of developing foot ulcers and on foot self-care.

4. Tripathy JP. Burden and risk factors of diabetes and hyperglycemia in India: findings from the Global Burden of Disease Study 2016. Diabetes Metab Syndr Obes. 2018;11:381-387. doi:10.2147/DMSO.S157376

5. Nyenwe EA, Jerkins TW, Umpierrez GE, Kitabchi AE. Management of type 2 diabetes: evolving strategies for the treatment of patients with type 2 diabetes. Metabolism. 2011;60(1):1-23. doi:10.1016/j.metabol.2010.09.010

6. Boutayeb A. The Burden of Communicable and Non-Communicable Diseases in Developing Countries. Handbook of Disease Burdens and Quality of Life Measures. 2010;531-546. doi:10.1007/978-0-387-78665-0_32

7. King H, Aubert RE, Herman WH. Global burden of diabetes, 1995-2025: prevalence, numerical estimates, and projections. Diabetes Care. 
Annals of International Medical and Dental Research

E-ISSN: 2395-2822 | P-ISSN: 2395-2814

Vol-8, Issue-1 | January-February 2022

DOI: 10.53339/aimdr.2022.8.1.38

Page no- 296-309 | Section- Research Article (Medicine)

1998;21(9):1414-31. doi: 10.2337/diacare.21.9.1414. PMID: 9727886.

8. Sayeed MA, Mahtab H, Akter Khanam P, Abdul Latif Z, Keramat Ali SM, Banu A, et al. Diabetes and impaired fasting glycemia in a rural population of Bangladesh. Diabetes Care. 2003;26(4):1034-9. doi: 10.2337/diacare.26.4.1034.

9. Singh N, Armstrong DG, Lipsky BA. Preventing foot ulcers in patients with diabetes. JAMA. 2005;293(2):217-28. doi: 10.1001/jama.293.2.217.

10. Yazdanpanah L, Shahbazian H, Nazari I, et al. Incidence and Risk Factors of Diabetic Foot Ulcer: A Population-Based Diabetic Foot Cohort (ADFC Study)-Two-Year Follow-Up Study. Int J Endocrinol. 2018;2018:7631659. doi:10.1155/2018/7631659

11. Pendsey SP. Understanding diabetic foot. Int J Diabetes Dev Ctries. 2010;30(2):75-79. doi:10.4103/0973-3930.62596

12. Boulton AJ, Vileikyte L, Ragnarson-Tennvall G, Apelqvist J. The global burden of diabetic foot disease. Lancet. 2005;366(9498):1719-24. doi: 10.1016/S0140-6736(05)67698-2.

13. Ramsey SD, Newton K, Blough D, McCulloch DK, Sandhu N, Reiber GE, et al. Incidence, outcomes, and cost of foot ulcers in patients with diabetes. Diabetes Care. 1999;22(3):382-7. doi: 10.2337/ diacare.22.3.382.

14. Vallianou N, Evangelopoulos A, Koutalas P. Alphalipoic Acid and diabetic neuropathy. Rev Diabet Stud. 2009;6(4):230-236. doi:10.1900/RDS.2009.6.230

15. Mørkrid K, Ali L, Hussain A. Risk factors and prevalence of diabetic peripheral neuropathy: A study of type 2 diabetic outpatients in Bangladesh. Int J Diabetes Dev Ctries. 2010;30(1):11-17. doi:10.4103/0973-3930.60004

16. Kärvestedt L, Mårtensson E, Grill V, Elofsson S, von Wendt G, Hamsten A, Brismar K. The prevalence of peripheral neuropathy in a population-based study of patients with type 2 diabetes in Sweden. J Diabetes Complications. 2011 Mar;25(2):97-106. doi: 10.1016/j.jdiacomp.2010.04.001.

17. Margolis DJ, Kantor J, Berlin JA. Healing of diabetic neuropathic foot ulcers receiving standard treatment. A meta-analysis. Diabetes Care. 1999;22(5):692-5. doi: 10.2337/diacare.22.5.692.

18. Norgren L, Hiatt WR, Dormandy JA, Nehler MR, Harris KA, Fowkes FG; TASC II Working Group. Inter-Society Consensus for the Management of
Peripheral Arterial Disease (TASC II). J Vasc Surg. 2007;45 Suppl S:S5-67. doi: 10.1016/j.jvs.2006.12.037.

19. Newman AB, Siscovick DS, Manolio TA, Polak J, Fried LP, Borhani NO, Wolfson SK. Ankle-arm index as a marker of atherosclerosis in the Cardiovascular Health Study. Cardiovascular Heart Study (CHS) Collaborative Research Group. Circulation. 1993;88(3):837-45. doi: 10.1161/01.cir.88.3.837.

20. Kasapis C, Gurm HS. Current approach to the diagnosis and treatment of femoral-popliteal arterial disease. A systematic review. Curr Cardiol Rev. 2009;5(4):296-311. doi:10.2174/157340309789317823

21. Rassias AJ, Marrin CA, Arruda J, Whalen PK, Beach $M$, Yeager MP. Insulin infusion improves neutrophil function in diabetic cardiac surgery patients. Anesth Analg. 1999;88(5):1011-6. doi: 10.1097/00000539199905000-00008.

22. Golden SH, Peart-Vigilance C, Kao WH, Brancati FL. Perioperative glycemic control and the risk of infectious complications in a cohort of adults with diabetes. Diabetes Care. 1999;22(9):1408-14. doi: 10.2337/diacare.22.9.1408.

23. Bagdade JD, Stewart M, Walters E. Impaired granulocyte adherence. A reversible defect in host defense in patients with poorly controlled diabetes. Diabetes care. 1978;27(6):677-81. doi: 10.2337/diab.27.6.677.

24. Doxey DL, Ng MC, Dill RE, Iacopino AM. Plateletderived growth factor levels in wounds of diabetic rats. Life Sci. 1995;57(11):1111-23. doi: 10.1016/00243205(95)02056-o.

25. Mansbridge JN, Liu K, Pinney RE, Patch R, Ratcliffe A, Naughton GK. Growth factors secreted by fibroblasts: role in healing diabetic foot ulcers. Diabetes Obes Metab. 1999;1(5):265-79. doi: 10.1046/j.1463-1326.1999.00032.x.

26. Lüscher TF. Prevention is better than cure: the new ESC Guidelines. Eur Heart J. 2016;37(29):2291-2293. doi:10.1093/eurheartj/ehw321

27. Al-Maskari F, El-Sadig M. Prevalence of risk factors for diabetic foot complications. BMC Fam Pract. 2007;8:59. doi: 10.1186/1471-2296-8-59.

28. Al-Mahroos F, Al-Roomi K. Diabetic neuropathy, foot ulceration, peripheral vascular disease and potential risk factors among patients with diabetes in Bahrain: a nationwide primary care diabetes clinic-based study. Ann Saudi Med. 2007;27(1):25-31. doi:10.5144/0256-4947.2007.25 
Annals of International Medical and Dental Research

E-ISSN: 2395-2822 | P-ISSN: 2395-2814

Vol-8, Issue-1 | January-February 2022

DOI: 10.53339/aimdr.2022.8.1.38

Page no- 296-309 | Section- Research Article (Medicine)

29. Latif ZA, Jain A, Rahman MM. Evaluation of management, control, complications and psychosocial aspects of diabetics in Bangladesh: DiabCare Bangladesh 2008. Bangladesh Med Res Counc Bull. 2011;37(1):11-6. doi: 10.3329/bmrcb.v37i1.7793.

30. Dòria M, Rosado V, Pacheco LR, et al. Prevalence of Diabetic Foot Disease in Patients with Diabetes Mellitus under Renal Replacement Therapy in Lleida, Spain. Biomed Res Int. 2016;2016:7217586. doi:10.1155/2016/7217586

31. Mørkrid K, Ali L, Hussain A. Risk factors and prevalence of diabetic peripheral neuropathy: A study of type 2 diabetic outpatients in Bangladesh. Int J Diabetes Dev Ctries. 2010;30(1):11-7. doi: 10.4103/0973-3930.60004.

32. Tapp RJ, Shaw JE, de Courten MP, Dunstan DW, Welborn TA, Zimmet PZ; AusDiab Study Group. Foot complications in Type 2 diabetes: an Australian population-based study. Diabet Med. 2003;20(2):10513. doi: 10.1046/j.1464-5491.2003.00881.x.

33. Tesfaye S, Stevens LK, Stephenson JM, Fuller JH, Plater M, Ionescu-Tirgoviste C, Nuber A, Pozza G, Ward JD. Prevalence of diabetic peripheral neuropathy and its relation to glycaemic control and potential risk factors: the EURODIAB IDDM Complications Study. Diabetologia. 1996;39(11):1377-84. doi: 10.1007/s001250050586.

34. Karmakar RN, Khandakar MR, Gangopadhyay PK, Ghosh K, Babu AS. Albuminuria and neuropathy in newly detected diabetics: profile and correlation. J Indian Med Assoc. 2011;109(6):396-9.

35. Lee M, Saver JL, Chang KH, Ovbiagele B. Level of albuminuria and risk of stroke: systematic review and meta-analysis. Cerebrovasc Dis. 2010;30(5):464469. doi:10.1159/000317069

36. Deckert T, Feldt-Rasmussen B, Borch-Johnsen K, Jensen $\mathrm{T}$, Kofoed-Enevoldsen A. Albuminuria reflects widespread vascular damage. The Steno hypothesis. Diabetologia. 1989;32(4):219-26. doi: 10.1007/BF00285287.

37. Hong X, Huang L, Zhang Y, Shen X, Weng S, Zeng F et al. Stronger Association of Albuminuria with the Risk of Vascular Complications than Estimated Glomerular Filtration Rate in Type 2 Diabetes. Kidney Blood Press Res 2021;46:550-562 DOI: 10.1159/000515163

38. Ostchega Y, Paulose-Ram R, Dillon CF, Gu Q, Hughes JP. Prevalence of peripheral arterial disease and risk factors in persons aged 60 and older: data from the National Health and Nutrition Examination Survey 1999-2004. J Am Geriatr Soc. 2007;55(4):5839. doi: 10.1111/j.1532-5415.2007.01123.x.

Source of Support: Nil, Conflict of Interest: None declared 